\title{
CHARACTERISTICS OF MOTILE CURVED RODS IN VAGINAL SECRETIONS
}

\author{
Mary S. Sprott, H. R. Ingham, R. S. Pattman*, Rosemary L. Eisenstadt, \\ G. R. Short, H. K. Narang, Penelope R. Sisson and J. B. Selkon \\ Regional Public Health Laboratory and * Department of Sexually Transmitted \\ Diseases, General Hospital, Newcastle upon Tyne NE4 6BE
}

\begin{abstract}
Summary. Motile curved rods seen in vaginal secretions have been isolated on Columbia agar supplemented with $5 \%$ human blood and vitamin $\mathrm{K}$. Growth occurred anaerobically and in $5 \%$ oxygen but not in more aerobic conditions. There were two distinct groups of these organisms, distinguishable by morphology, biochemical activity and susceptibility to metronidazole. All isolates were sensitive to a wide range of antimicrobial agents, with the exception of nalidixic acid and polymyxin, but one group was resistant to metronidazole. There was little difference between the results of tests of susceptibility to aminoglycosides or to metronidazole performed in anaerobic and microaerophilic conditions. Motile curved rods were isolated from 18 of 80 patients with a clinical diagnosis of non-specific vaginitis, but from only two of 39 without the disease.
\end{abstract}

\section{INTRODUCTION}

Curved rods with a characteristic motility have been reported in vaginal secretions of patients with a clinical diagnosis of non-specific vaginitis (NSV) (Hjelm et al., 1981; Skarin et al., 1981; Phillips and Taylor, 1982; Sprott et al., 1982). In this paper we report on the morphology, cultural and biochemical characteristics, and the susceptibility to antimicrobial agents, of such organisms isolated in this laboratory.

\section{Materials AND Methods}

Patients. One hundred and nineteen patients attending the Department of Sexually Transmitted Diseases, Newcastle General Hospital, were included in the study.

Specimens. Gram-stained smears from urethral and endocervical swabs were examined by microscopy for gram-negative diplococci and the swabs were plated on Modified New York City Medium (Young, 1978) for the isolation of Neisseria gonorrhoeae. A second endocervical swab was placed in transport medium for inoculation on to McCoy cells for the isolation of Chlamydia trachomatis. The discharge from the posterior vaginal pool was suspended in normal saline and smears were examined by dark ground microscopy for yeasts, Trichomonas vaginalis and motile curved rods. Gram-stained smears for microscopy were prepared by a technique in which decolorisation was performed by applying acetone for 2-3 $\mathrm{s}$. Swabs from the posterior vaginal pool were cultured for Gardnerella vaginalis and curved rods. 
Culture media and growth conditions. The medium for primary isolation and all subsequent studies of the growth of motile curved rods and G. vaginalis was Columbia Agar Base (Lab M) supplemented with human blood $5 \%$ and vitamin $\mathrm{K} 1 \mathrm{mg} / \mathrm{L}$ (CBA). After inoculation, plates were incubated at $37^{\circ} \mathrm{C}$ for at least $48 \mathrm{~h}$ in $90 \% \mathrm{H}_{2}$ and $10 \% \mathrm{CO}_{2}$ in an anaerobic jar fitted with a cold palladium catalyst (Don Whitley Scientific Ltd, Green Lane, Baildon, Shipley, West Yorks). All curved rods were subsequently subcultured (i) aerobically, (ii) in $5 \% \mathrm{CO}_{2}$ in a candle jar, and (iii) in $10 \% \mathrm{CO}_{2}$ in a Gas $\mathrm{Kit} \mathrm{CO}_{2}$ system (Oxoid), at $37^{\circ} \mathrm{C}$ for 4 days.

Fluid media used were Todd-Hewitt Broth (Oxoid) and Robertson's Cooked Meat Medium (Difco) with and without haemin $(5 \mathrm{mg} / \mathrm{L})$, sodium formate $(2 \mathrm{~g} / \mathrm{L})$, sodium fumarate $(3 \mathrm{~g} / \mathrm{L})$ and vitamin $\mathrm{K}(1 \mathrm{mg} / \mathrm{L})$. These were incubated anaerobically and growth was determined by viable counts on CBA performed by the method of Miles, Misra and Irwin (1938).

The ability of the isolates to grow in microaerophilic conditions was examined by incubation in anaerobic jar without a catalyst. In a series of experiments, partial removal of air by evacuation was monitored with an Edwards pressure gauge and the pressure in the jar was restored to atmospheric pressure by admission of $10 \% \mathrm{CO}_{2}$ in $\mathrm{H}_{2}$, leaving final concentrations of oxygen from 0.3 to $7 \%$.

Gram-variable coccobacilli that showed enhancement of growth by $10 \% \mathrm{CO}_{2}$ or in anaerobic conditions, $\beta$-haemolysis on CBA, and a zone of inhibition around a disk containing $100 \mu \mathrm{g}$ of metronidazole, were identified as G. vaginalis (Taylor et al., 1982).

Characterisation of motile curved rods. Motility was examined by dark-ground microscopy of the water of condensation from 24-h CBA-slope cultures of each strain. Because in preliminary studies these organisms failed to grow consistently in liquid media, the inoculum for all biochemical tests was taken directly from CBA plates incubated at $37^{\circ} \mathrm{C}$ for $48 \mathrm{~h}$. Hippurate hydrolysis (Skirrow and Benjamin, 1982) and arginine hydrolysis (Thornley, 1960) were examined after incubating the inoculated media aerobically at $37^{\circ} \mathrm{C}$ for 2 and $24 \mathrm{~h}$ respectively. The aesculin hydrolysis test (Rotimi, Faulkner and Duerden, 1980) was incubated both aerobically and anaerobically and examined after $24 \mathrm{~h}$, and the ONPG test (Lowe, 1962) was incubated aerobically for $24 \mathrm{~h}$. Indole production was tested by both Kovacs' and Ehrlich's reagents (Cowan, 1974) using 48-h cultures in cooked meat medium. For each of the following tests, the first of the methods described by Cowan (1974) was used: nitrate reduction (incubated anaerobically for 3 or 7 days), oxidase, and urease. Catalase production was tested by transferring organisms from a colony to a drop of hydrogen peroxide on a glass slide.

Electron microscopy. Organisms grown on CBA were fixed and embedded by the methods of Narang (1982). Thin sections (50 $\mathrm{nm}$ ) were stained with uranyl acetate and lead citrate and examined at $60 \mathrm{kV}$ in an AEI electron microscope. In addition, grids for electron microscopy were prepared with organisms in the water of condensation from 24-h CBA-slope cultures. The cells were washed by resuspending the centrifuged deposit in phosphate buffered saline followed by centrifugation at $1200 \mathrm{~g}$ for $15 \mathrm{~min}$, this procedure being repeated three times. Grids were prepared by low speed centrifugation as described by Narang and Codd (1979), except that the washed bacterial suspension was examined both undiluted and at a dilution of 1 in 10 . The prepared grids were negatively stained with phosphotungstic acid $(p \mathrm{H} \mathrm{6.6)}$ and examined by electron microscopy.

Antimicrobial sensitivity tests. The antimicrobial agents tested were penicillin, tetracycline, lincomycin, erythromycin, chloramphenicol, polymyxin, nalidixic acid, streptomycin, gentamicin, metronidazole and the hydroxy-metabolite of metronidazole-1-2(hydroxyethyl)-2-hydroxymethyl-6-nitroimidazole. Minimum inhibitory concentrations (MIC) of the above agents were determined by incorporating twofold dilutions in CBA. Growth from agar plates incubated for $48 \mathrm{~h}$ was suspended in saline to give $c .10^{8} \mathrm{cfu} / \mathrm{ml}$ and inoculated on to the plates with a Denley Multipoint inoculator delivering $0.01 \mathrm{ml}$. Plates were read after incubation anaerobically for $48 \mathrm{~h}$ at $37^{\circ} \mathrm{C}$; the end point was the lowest concentration that totally inhibited growth. In addition the MIC of metronidazole, gentamicin and streptomycin was determined in microaerophilic conditions. Control organisms were Staphylococcus aureus strain NCTC 6571 , Pseudomonas aeruginosa strain NCTC 10662, Bacteroides fragilis strain NCTC 8560 and strains of Escherichia coli and B. asaccharolyticus isolated and characterised in this laboratory by the methods of Cowan (1974) and Duerden et al. (1976). 


\section{RESULTS}

Of the 119 patients examined, 33 did not have a vaginal discharge. N. gonorrhoeae, Chlamydia trachomatis, Candida species or G. vaginalis were isolated from two thirds of these patients, but motile curved rods were found in only two (table I). Specimens from most of the other 86 patients (with vaginal discharge) yielded one or more of these named organisms or T. vaginalis, and motile curved rods were isolated from 18 .

Gram-stained smears from some patients with increased vaginal secretions showed few pus cells and a mixture of organisms, including curved rods that stained poorly when counterstained with neutral red but better when dilute carbol fuchsin was used. These curved organisms grew on CBA, appearing as minute transparent or grey colonies after incubation anaerobically for $48 \mathrm{~h}$. Although vitamin $\mathrm{K}$ was included in the medium, subsequent studies have indicated that it was not a required growth factor. Morphologically, two types were distinguishable. Eight strains were short curved rods (SCR) 1-2 $\mu \mathrm{m}$ in length; all cells retained some violet dye, and this was more marked after repeated subculture. The remaining 12 strains were long curved rods (LCR) $2-4 \mu \mathrm{m}$ in length, which appeared red, though often with a central violet area. The LCR strains produced $\alpha$-haemolysis after prolonged culture on CBA and developed a dark brown pigment after incubation for 10-14 days. Both groups of organisms were very motile with a rapid darting movement; larger forms of the LCR strains also showed serpentine movements. Attempts to grow isolates in liquid media were disappointing. In Robertson's cooked meat medium and Todd-Hewitt broth, with an initial inoculum of $10^{4}-10^{6}$ organisms, the viable count after incubation for $48 \mathrm{~h}$ was in the range $3 \times 10^{6}-3 \times 10^{7} \mathrm{cfu} / \mathrm{ml}$. The addition of sodium formate, sodium fumarate, haemin and vitamin $\mathrm{K}$ did not improve growth.

Electron microscopy revealed curved rods of varied size. The SCR had a diameter of c. $0.3 \mu \mathrm{m}$, rounded ends, and 2-6 subpolar flagella with a common point of origin on the concave side (fig. 1). The LCR had flagella arising from several different points (fig. 2).

All strains of the curved rods gave negative results in tests for catalase, oxidase, urease and indole production. Other biochemical characteristics are shown in table II;

TABLE I

Motile curved rods and other microorganisms isolated from the vagina in 119 patients

\begin{tabular}{|c|c|c|}
\hline \multirow[b]{2}{*}{ Organisms } & \multicolumn{2}{|c|}{ Number of isolates from } \\
\hline & $\begin{array}{l}33 \text { patients with } \\
\text { no vaginal discharge }\end{array}$ & $\begin{array}{l}86 \text { patients with } \\
\text { vaginal discharge }\end{array}$ \\
\hline $\begin{array}{l}\text { Neisseria gonorrhoeae } \\
\text { Chlamydia trachomatis } \\
\text { Candida spp. } \\
\text { Trichomonas vaginalis } \\
\text { Gardnerella vaginalis } \\
\text { Motile curved rods }\end{array}$ & $\begin{array}{l}2 \\
2 \\
9 \\
0 \\
7 \\
2 \ddagger\end{array}$ & $\begin{array}{r}7^{*} \\
15^{*} \\
4^{*} \\
6 \dagger \\
48^{*} \\
18^{*} \S\end{array}$ \\
\hline
\end{tabular}

* Clinical diagnosis of non-specific vaginitis.

$\dagger$ One patient also had $N$. gonorrhoeae and one had Candida.

$\ddagger$ One patient also had $N$. gonorrhoeae and $C$. trachomatis.

$\S$ Two patients also had $N$. gonorrhoeae, two had $C$. trachomatis and nine had $G$. vaginalis. 


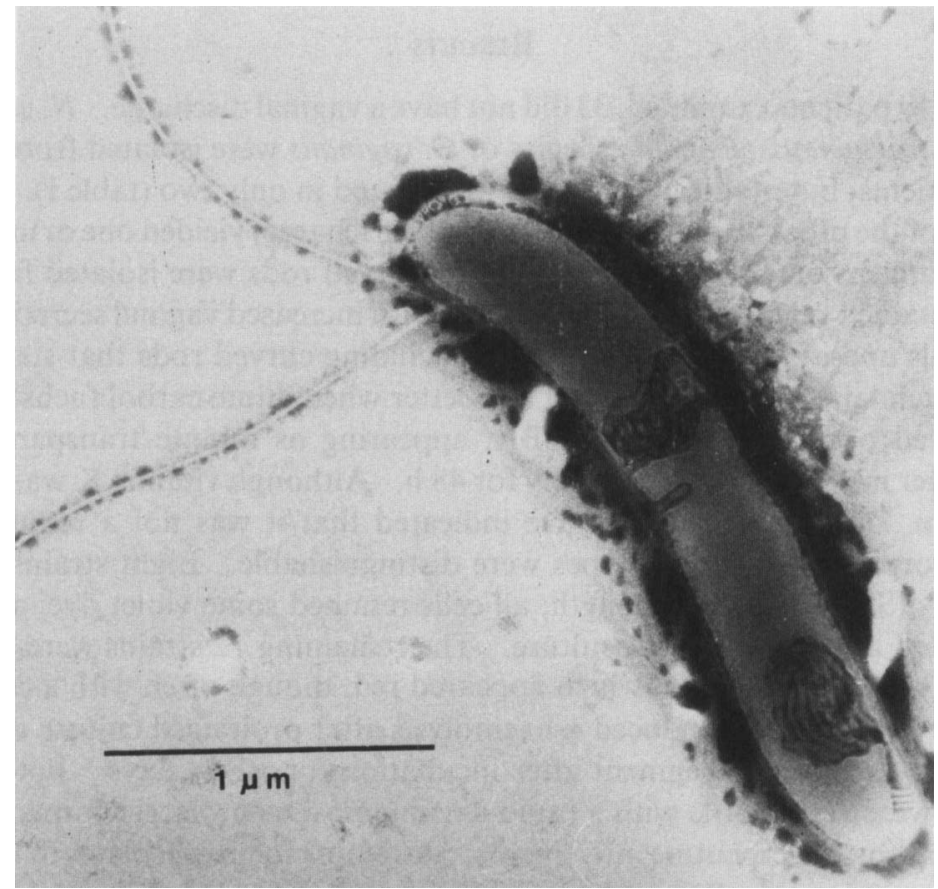

FIG. 1.-Electron micrograph of a pair of short curved rods (SCR) showing two subpolar flagella on the concave side on one of the rods.

with some exceptions, the SCR gave positive reactions and the LCR negative reactions in the ONPG, maltose-utilisation and nitrate-reduction tests and in tests for the hydrolysis of hippurate and arginine.

Table III shows that the growth of both groups was affected similarly by different atmospheric conditions. There was no growth aerobically or in $5-10 \% \mathrm{CO}_{2}$ (candle

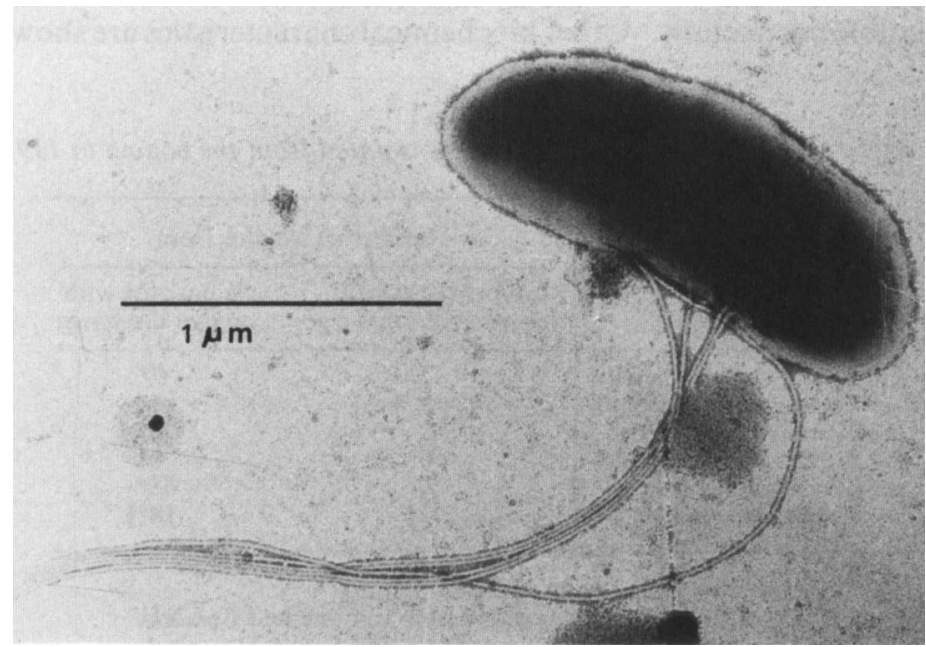

FIG. 2.-Electron micrograph of a long curved rod (LCR) showing several flagella with different points of origin on the concave side. (This is an unusually short cell from an LCR culture.) 
TABLE II

Characteristics of motile curved rods

\begin{tabular}{|c|c|c|}
\hline Character & $\begin{array}{l}\text { Short curved } \\
\text { rods }\end{array}$ & $\begin{array}{l}\text { Long curved } \\
\text { rods }\end{array}$ \\
\hline $\begin{array}{l}\text { Growth on } 5 \% \\
\text { human-blood agar } \\
\text { Reaction in } \\
\text { Gram's stain } \\
\text { ONPG } \\
\text { Hippurate } \\
\text { hydrolysis } \\
\text { Arginine } \\
\text { hydrolysis } \\
\text { Maltose RCUT } \\
\text { Reduction of } \\
\text { nitrate }\end{array}$ & $\begin{array}{c}\text { No haemolysis } \\
\text { colonies white } \\
\text { Positive } \\
+ \\
+ \\
+ \\
+* \\
+ \\
+1-\end{array}$ & $\begin{array}{l}\alpha \text {-haemolysis } \\
\text { colonies brown } \\
\text { Variable } \\
- \\
- \\
- \\
- \\
-\end{array}$ \\
\hline
\end{tabular}

ONPG $=o$-nitrophenyl- $\beta$-galactopyranoside test for $\beta$ galactosidase.

RCUT = rapid carbohydrate utilisation test.

$+=$ positive; $-=$ negative reaction.

$+/-=$ variable reaction (four of eight isolates positive).

* One isolate negative.

† One isolate positive.

TABLE III

Growth of motile curved rods and control organisms in different atmospheric conditions

\begin{tabular}{|c|c|c|c|c|c|c|c|c|}
\hline \multirow[b]{3}{*}{ Organism } & \multicolumn{8}{|c|}{ Growth $(+)$ or absence of growth $(-)$ of the organisms in } \\
\hline & \multirow{2}{*}{$\begin{array}{l}\text { Aerobic } \\
\text { conditions }\end{array}$} & \multirow[b]{2}{*}{$\mathrm{CO}_{2}^{*}$} & \multirow{2}{*}{$\begin{array}{l}\text { Anaerobic } \\
\text { conditions }\end{array}$} & \multicolumn{5}{|c|}{ Oxygen concentration of } \\
\hline & & & & $0.3 \%$ & $0 \cdot 4 \%$ & $1 \%$ & $5 \%$ & $7 \%$ \\
\hline $\left.\begin{array}{l}\text { Short curved rods } \\
\text { Long curved rods }\end{array}\right\}$ & - & - & + & + & + & + & + & - \\
\hline$P$. aeruginosa NCTC 10662 & + & + & - & + & + & + & + & + \\
\hline B. fragilis NCTC 8560 & - & - & + & + & + & + & - & - \\
\hline B. asaccharolyticus & - & - & + & + & + & - & - & - \\
\hline
\end{tabular}

* $5 \%$ and $10 \%$ (candle jar and Gas Kit system).

jar or Gas Kit system), but all strains grew anaerobically and in concentrations of oxygen up to $5 \%$. For comparison, $B$. fragilis grew in concentrations of oxygen up to only $1 \%$, and $B$. asaccharolyticus up to only $0.4 \%$. In contrast, Pseudomonas aeruginosa failed to grow anaerobically but grew in a concentration of oxygen as low as $0 \cdot 3 \%$.

All strains were very sensitive to the antimicrobials tested, with the exceptions of nalidixic acid, polymyxin and metronidazole (table IV). There was a notable difference between the two groups in their sensitivity to metronidazole, the range of MIC being $0.5-4 \mathrm{mg} / \mathrm{L}$ for the LCR, but $16-1000 \mathrm{mg} / \mathrm{L}$ for the SCR. The levels of MIC of metronidazole, however, were similar when each strain was tested in anaerobic conditions and in the presence of $1 \%$ oxygen. When the organisms were re-tested with gentamicin and streptomycin in increased oxygen concentrations, the MIC remained the same or showed at most a two-fold reduction. In contrast the MIC of these 
TABLE IV

Minimal inhibitory concentrations (MIC) of antimicrobial agents tested anaerobically

\begin{tabular}{l|cc}
\hline & \multicolumn{2}{|c}{ Range of MIC in mg/L } \\
\cline { 2 - 3 } \multicolumn{1}{c|}{ Antimicrobial } & Short curved rod & Long curved rod \\
\hline Penicillin & $0.0075-0.06$ & $0 \cdot 0019-0.03$ \\
Tetracycline & $0 \cdot 125-8 \cdot 0$ & $0 \cdot 062-0 \cdot 25$ \\
Lincomycin & $<0.062-0 \cdot 25$ & $<0 \cdot 062$ \\
Erythromycin & $0 \cdot 03$ & $<0.015$ \\
Chloramphenicol & $<0 \cdot 5$ & $<0.5$ \\
Polymyxin & 128 & $64-128$ \\
Gentamicin & $0.5-1.0$ & $1.0-2$ \\
Streptomycin & $8-16$ & $4-8$ \\
Nalidixic acid & 128 & $32-128$ \\
Metronidazole & $16->1000$ & $0.5-4$ \\
Hydroxy-metabolite & $8->500$ & $0.5-2$ \\
of metronidazole & & \\
\hline
\end{tabular}

aminoglycosides for $S$. aureus strain NCTC 6571 and $E$. coli was 16-32 times higher in anaerobic conditions than when tested in microaerophilic conditions.

\section{DISCUSSION}

Motile curved bacilli were first isolated from the vagina by Curtis (1913) who described them as strictly anaerobic and gram-negative with up to six flagella. Moore (1954) in a subsequent study of curved rods from the vagina described them as "more or less gram negative" with a single flagellum; he also reported a similar organism with up to six flagella, which produced haemolysis on blood agar. Recently other workers have reported motile curved rods in vaginal discharge from women with NSV: Hjelm et al. (1981) found them in $30 \%$ of such patients, Skarin et al. (1981) in $8.6 \%$ and Phillips and Taylor (1982) in $11 \%$. In the present study, $18(22.5 \%)$ of 80 patients with NSV harboured the organism compared with two $(5 \cdot 1 \%)$ of 39 without the disease. Our findings indicate that these curved rods constitute two distinct groups distinguishable by their colonial appearance, microscopic morphology, biochemical reactions and sensitivity to metronidazole. It is clear that the prevalence rates already reported provide only limited information in view of the ill-defined taxonomic status of these organisms.

Their cultural requirements are unusual: they grow well anaerobically but, unlike obligate anaerobes, they also grow in $5 \%$ oxygen although not in higher concentrations. Despite their ability to grow in the presence of oxygen the LCR are very sensitive to metronidazole (MIC 0.5-4 mg/L) and even the SCR (MIC 16-1000 mg/L) are more sensitive than facultative anaerobes (Fuzi and Csukas, 1970; Prince et al., 1969). In this respect these organisms resemble $G$. vaginalis, but unlike the latter they are only marginally more sensitive to the hydroxy-metabolite of metronidazole (Ralph and Amatnieks, 1980). Further evidence of the unusual metabolism of these organisms is their sensitivity to the aminoglycosides in both anaerobic and microaerophilic conditions. Normally, obligate anaerobes are highly resistant to these agents and, as our findings confirm, facultative anaerobes are much less sensitive in anaerobic 
conditions than in the presence of oxygen (Bondi, Dietz and Spaulding, 1946; Verklin and Mandell, 1977).

It appears, therefore, that these organisms represent a new group of bacteria, probably first reported by Curtis (1913). They appear to be distinct from the anaerobic bacteria isolated by Fontaine et al.(1982) from men with urethritis. Unlike our isolates, these were oxidase positive and motile with polar flagella; it was suggested that they were related to Vibrio succinogenes. Less certain is the relationship between our strains and those described by Skarin et al. (1981) and Spiegel et al. (1981) which had characteristics consistent with Wolinella succinogenes. Although some strains of Wolinella grow well in the presence of $5 \%$ oxygen they have polar flagella and their sensitivity to antimicrobials differs markedly from that of our isolates (Tanner et al., 1981).

Clearly the variety of these organisms is such that further taxonomic studies are required before their possible aetiological role in NSV can be established. Such studies are being carried out in this laboratory.

We wish to thank May and Baker Ltd, Dagenham, Essex, for donating the hydroxy metabolite of metronidazole, 1-2-(hydroxyethyl)-2-hydroxymethyl-6-nitroimidazole. We also thank Mrs A. Chappell and Mrs C. Laidlow for typing the manuscript.

\section{REFERENCES}

Bondi, A., Dietz, C. C. AND Spaulding, E. H. 1946. Interference with the antibacterial action of streptomycin by reducing agents. Science, 103, 399-401.

Cowan, S. T. 1974. Cowan and Steel's manual for the identification of medical bacteria, 2nd ed., Cambridge University Press, Cambridge.

CuRTIS, A. H. 1913. A motile curved anaerobic bacillus in uterine discharges. Journal of Infectious Diseases, 12, 165-169.

Duerden, B. I., HolbrooK, W. P., Collee, J. G. AND WatT, B. 1976. The characterization of clinically important gram negative anaerobic bacilli by conventional bacteriological tests. Journal of Applied Bacteriology, 40, 163-188.

Fontaine, E.A., TAYlor-Robinson, D., Borriello, S. P., Hanna, N. F. and Honour, P. 1982. Anaerobic bacteria in lower genital-tract infections. Lancet, 1, 281.

FuZI, M. AND CsuKAS, Z. 1970. Das antibakterielle Wirkungsspektrum des Metronidazols. Zentralblatt fur Bakteriologie, Parasitenkunde Infectionskrankheiten und Hygiene (Abteilung), 213, 258-262.

Huelm, E., Hallen, A., Forsum, U. and Wallin, J. 1981. Anaerobic curved rods in vaginitis. Lancet, 2, 1353-1354.

LowE, G. H. 1962. The rapid detection of lactose fermentation in paracolon organisms by the demonstration of $\beta$-D-galactosidase. Journal of Medical Laboratory Technology, 19, 21-25.

Miles, A. A., MisRa, S. S. AND IRwin, J. O. 1938. The estimation of the bactericidal power of blood. Journal of Hygiene, Cambridge, 38, 732-749.

MOORE, B. 1954. Observations on a group of anaerobic vaginal vibrios. Journal of Pathology and Bacteriology, 67, 461-473.

NARANG, H. K. AND CODD, A. A. 1979. A low-speed centrifugation technique for the preparation of grids for direct virus examination by electron microscopy. Journal of Clinical Pathology, 32, 304-305.

NARANG, H. K. 1982. Embedding bacteria and tissue culture cells for electron microscopy. Medical Laboratory Sciences, 39, 87-89.

Phillips, I. AND TAYLOR, E. 1982. Anaerobic curved rods in vaginitis. Lancet, 1, 221.

Prince, H. N., Grunberg, E., Titsworth, E. and Delorenzo, W. F. 1969. Effects of 
1-(2-nitro-1-imidazolyl)-3-methoxy-2-propanol and 2-methyl-5-nitroimidazole-1-ethanol against anaerobic and aerobic bacteria and protozoa. Applied Microbiology, 18, 728-730.

RALPH, E. D. AND AMATNIEKS, Y. E. 1980. Relative susceptibilities of Gardnerella vaginalis (Haemophilus vaginalis), Neisseria gonorrhoeae and Bacteroides fragilis to metronidazole and its two major metabolites. Sexually Transmitted Diseases, 7, 157-160.

ROTIMI, V. O., FAULKNER, J. AND DUERDEN, B. I. 1980. Rapid methods for identification of clinical isolates of Gram-negative anaerobic bacilli. Medical Laboratory Sciences, 37, 331-339.

Skarin, A., Spiegel, C. A., Westrom, L., Holmes, K. K. and Mardh, P. A. 1981. Demonstration of a strictly anaerobic, Gram-negative, comma-shaped bacterium in females with symptoms of lower genital tract infection. In: Abstracts of 4th International Meeting on Sexually Transmitted Diseases. (Heidelberg, October 18-20). p. 9.

SKIRROW, M. B. AND BENJAMIN J. 1982. The classification of 'thermophilic' campylobacters and their distribution in man and domestic animals. In: Campylobacter Epidemiology, Pathogenesis and Biochemistry. 1st ed., edited by Newel, D. G. MTP Press Ltd., Lancaster.

Spiegel, C. A., Skarin, A., MARDH, P. A. AND Holmes, K. K. 1981. Isolation and characterisation of a curved motile anaerobic organism associated with non-specific vaginitis. In: Abstracts of 4th International Meeting on Sexually Transmitted Diseases. (Heidelberg, October 18-20). p. 8.

Sprott, M. S., Pattman, R. S., Ingham, H. R., Short, G. R., Narang, H. K. and Selkon, J. B. 1982. Anaerobic curved rods in vaginitis. Lancet. $1,54$.

Tanner, A. C. R., Badger, S., Lai, C. H., Listgarten, M. A., Visconti, R. A. and Socransky, S. S. 1981. Wolinella gen. nov., Wolinella succinogenes (Vibrio succinogenes Wolin et al.) comb. nov., and Description of Bacteroides gracilis sp. nov., Wolinella recta sp. nov., Campylobacter conscisus sp. nov., and Eikenella corrodens from Humans with Periodontal Disease. International Journal of Systemic Bacteriology, 31, 432-445.

TAylor, E., Blackwell, A. L., Barlow, D. AND PhilliPS, I. 1982. Gardnerella vaginalis, anaerobes, and vaginal discharge. Lancet, 1, 1376-1379.

THORNLEY, M. J. 1960. The differentiation of Pseudomonas from other Gram-negative bacteria on the basis of arginine metabolism. Journal of Applied Bacteriology, 23, 37-52.

VerkLIN, R. M. AND MANDELl, G. L. 1977. Alteration of effectiveness of antibiotics by anaerobiosis. Journal of Laboratory and Clinical Medicine, 89, 67-71.

Young, H. 1978. Cultural diagnosis of gonorrhoea with modified New York City (MNYC) medium. British Journal of Venereal Diseases, 54, 36-40. 